\title{
El género biográfico: reflexiones y experiencias personales
}

\author{
The Genre of Biography: \\ Reflections and Personal Experiences
}

\author{
José Ortiz Monasterio \\ (D) orcid.org/0000-0003-4323-6104 \\ Instituto de Investigaciones Dr. José María Luis Mora, México \\ jortiz@institutomora.edu.mx
}

Resumen: El género biográfico, de tan antiguo y tan extendido, requiere un análisis de larga duración. Se detecta la aparición de la biografía desde las tablillas de barro que cuentan la vida de Gilgamesh y su angustia por la muerte. Se advierte que no es posible comprender un texto de hace 5000 años sin reconstruir el horizonte de expectativas de la época. Esta angustia por la muerte también está presente en Netzahualcóyotl. De otra manera, más didáctica y moral comentamos las vidas de Plutarco, modelo para los biógrafos de siglos por venir. Se intenta entrelazar autores mexicanos y extranjeros para dar lo que podríamos llamar efecto carrusel, donde los autores mexicanos obtienen la universalidad. En la segunda parte comento algunas experiencias personales en torno al género biográfico que abarcan diversos subgéneros, desde las biografías colectivas hasta mi biografía de Vicente Riva Palacio y un acercamiento literario a la vida de Vicente Guerrero Saldaña.

Palabras clave: biografía universal; biografía México; prosopografía.

Abstract: The genre of biography is so well-established and extensive that it requires a long-term analysis. Biographies have been written since clay tablets were used to tell the story of Gilgamesh and his anguish about death. It is impossible to understand a 5000 year old text without reconstructing the 
horizon of expectations of the time. Netzahualcoyotl was also anxious about death. In a more didactic, moral manner, we can discuss Plutarch's lives, the model for other biographers for centuries. This essay brings together Mexican and foreign authors to create what could be called "the carousel effect", where Mexican authors obtain universality. In the second part, I share a number of personal experiences relating to the genre of biography and approaches to a variety of sub-genres, from collective biographies to my work on Vicente Riva Palacio and a literary approach to the life of Vicente Guerrero Saldaña.

Key words: universal biography, Mexican biography, prosopography.

\section{BREVE HISTORIA DEL PROBLEMA}

T a prueba de que Gilgamesh existió realmente, que no fue sólo una leyenLda mitológica, reside en que su mayor afán era buscar la inmortalidad, lo cual sólo interesaría a quien fuera mortal. Se dice que nacer es naufragar $y$, en efecto, la muerte, como límite inexorable es un rasgo fundamental de los seres vivos, pero sólo los seres humanos tienen conciencia de ello.

La angustia por la muerte, tan antigua como Gilgamesh, o tal vez anterior a él, parece ser un rasgo humano tan perdido en el tiempo como el tabú del incesto. Pero el lenguaje brinda una salida que consuela, pero no evita esa muerte: escribir la vida de hombres y mujeres para que no se pierda la memoria de los grandes y no tan grandes personajes de la historia. Las tablillas de arcilla que se han encontrado en Babilonia dan fe de que Gilgamesh, rey de Uruk, fue un personaje real que después se transformó en personaje legendario. Y la epopeya delata, en diferentes pasajes, la angustia por la muerte. Debe leerse con reservas un texto escrito hace más de 5000 años:

como caña de cañaveral

se quiebra

aun el joven lleno de salud

aun la joven llena de salud.

No hay quien haya visto la muerte

la muerte nadie

le ha visto la cara.

A la muerte nadie 
le ha oído la voz.

Pero, cruel quiebra la muerte

a los hombres.

(Gilgamesh, 2016, p. 160)

Netzahualcóyotl, rey de Texcoco, en otro tiempo y lugar cantó la visión náhuatl del carácter perecedero no sólo de la vida, sino del arte:

Yo Netzahualcóyotl lo pregunto:

¿acaso de veras se vive con raíz en la tierra?

No para siempre en la tierra:

Sólo un poco aquí.

Aunque sea de jade se quiebra,

aunque sea oro se rompe,

aunque sea plumaje de quetzal se desgarra.

No para siempre en la tierra:

Sólo un poco aquí.

(León-Portilla, 1984, p. 49)

La fascinación de los antiguos egipcios por la muerte es bien conocida. Muy a propósito del tema de la biografía es la teoría de la nariz de Cleopatra, muy en boga en el siglo xix, según la cual si sus narinas hubieran sido menos abiertas o el caballete más pronunciado la historia universal hubiera sido muy distinta; lo particular dominando lo general. Esto es llevar la teoría del grande hombre (o mujer) a un grado superlativo, pero fue motivo de innumerables discusiones eruditas. Un dejo de verdad tiene, sin embargo, si se le da el sentido de que algo mínimo puede producir algo máximo; por ejemplo: no hay que confundir el incendio que viene con una revolución, con la chispa que la provocó.

Plutarco de Queronea es sin duda entre todos el biógrafo más célebre, pero a la distancia de poco más de 2000 años me pregunto si lo podemos

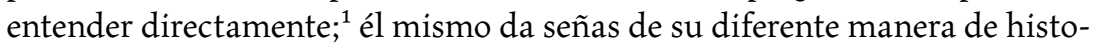
riar: "Haré porque, purificado en mi narración lo fabuloso, tome forma de historia; más si hubiere alguna parte que obstinadamente se resistiese a la probabilidad y no se prestase a hacer unión con lo verosímil, necesitaremos

${ }^{1}$ La construcción de la visión idealizada de los griegos es explicada por Bernal (1987).

\section{()(1)}


en cuanto a ella de lectores benignos y que no desdeñen el estudio de las antigüedades" (Plutarco, 1973, p. 36).

Se ha dicho una y mil veces que Aristóteles tuvo como pupilo a Alejandro Magno y que gran influencia ejerció sobre él. Pero no hay que perder de vista el otro lado de esta relación: Aristóteles sabía muy bien que él orbitaba en el centro del Estado y pudo sentir la fuerza del poder. Por supuesto Aristóteles, a diferencia de otros filósofos, defiende el derecho de conquista. Dice Plutarco (1973) en la vida de Alejandro:

Porque habiendo [Alejandro] entendido después de haber pasado ya al Asia que Aristóteles había publicado en sus libros algunas de estas doctrinas, le escribió, hablándole con desenfado sobre la materia, una carta de que es copia la siguiente: "Alejandro a Aristóteles, felicidad. No has hecho bien en publicar las doctrinas acromáticas; porque ¿en qué nos diferenciamos de los demás, si las ciencias en que nos has instruido han de ser comunes a todos? Pues yo más quiero sobresalir en los conocimientos útiles y honestos que en el poder" (p. 708).

La virtud de sus héroes queda escrita para que el hombre libre culto (no los esclavos que había por todas partes) sacara una lección que lo acercara a la virtud y lo hiciera aborrecer el vicio. Este aspecto didáctico hizo que Plutarco (1973) se convirtiera en uno de los autores más leídos de todos los tiempos. "La virtud natural -escribe Plutarco- se aventaja a todo estudio y arte" (p. 39).

Además de las vidas de los santos, las novelas de caballería son, durante la Edad Media, un remedo de biografías y siguen siendo modelos de una vida ejemplar. Es curioso que en una época en la que todos creían en el más allá nadie quería, salvo los místicos, dejar el más acá.

El Mio Cid a mí me sigue gustando, especialmente en las ediciones que confrontan el castellano medieval con el moderno. Y nos recuerdan que muchas obras fundamentales, como La Ilíada, primero se cantaron en las fiestas y mucho después fueron conservadas en forma escrita. Hay ahora cierto desprecio por la memoria, que no se conoció en otras épocas. Especialmente las composiciones rimadas pueden recordarse fácilmente. ¿Cómo es posible dirigir una sinfonía sin partituras? La memoria es una facultad humana, que debe aprovecharse, aunque no privilegiarse.

\section{()(1) $\$$}


Se ha dicho que fue la Edad Media una época oscura, pero se olvida que la alumbró Leonor de Aquitania, bellísima, sapientísima y esforzadísima capitana en la segunda Cruzada. También se olvida que entonces se escribieron El conde Lucanor por don Juan Manuel y La Celestina por Fernando de Rojas, faros de la cultura universal de muy sabrosa lectura que tienen, a mi parecer, un fondo biográfico verdadero.

En el Renacimiento predomina aún el enfoque biográfico, por ejemplo, siguiendo la cronología de las vidas de los príncipes (los ciudadanos principales) y la preeminencia de lo particular sobre lo general. Para Guicciardini (1969):

Truth resides therefore in the specific instance, in the particolare, in the clash of egotisms as these work themselves in great events. And yet, his cold surgical eye fixed on this cause, cautios Francesco Guicciardini does not conclude that he has isolated the cause. No historian was ever less monomaniacal. Even thoug he would seam to have tracked the motive power down to its source in individual behavior -more specially individual ambition- ultimately all is mistery, for all rests in the hands of Fortuna (p. xVII).

En las obras que escribieron los cronistas de Nueva España, Cortés es retratado en algunas para ensalzarlo y en otras para disminuirlo y son en gran medida biografías del conquistador. Cortés no entra en el panteón del nacionalismo mexicano y, para condenarlo definitivamente, se le deja fuera con el tajo torpe de fingir que nuestra historia comienza en 1810 . O tal vez el problema sea que la desigualdad actual, como por ensalmo, se le endilga al conquistador.

Es más fácil escribir una biografía que sufrir esa vida. Quizá por ello Cervantes -hombre de pluma y también de acción- asevera que es más pasable la vida del escritor, por más dolores de cabeza que le aquejen, que la del soldado, porque este siempre está a punto de perder la vida. El valor personal ha sido siempre muy estimado en los héroes; quienes conocen dicen que llega un punto en que la vida ya no estorba.

Los dramas históricos de William Shakespeare buscan lo humano universal más que lo biográfico; nada para explicar la ambición deschavetada que poner en escena a Macbeth; nada para levantar el espíritu nacional que representar a Enrique V, del que ahora nos llama la atención las abultadas ci-

\section{()(1) $\$$}


fras de los enemigos muertos en la batalla de Agincourt, más subidas que las que provocaba Alejandro el Grande quien, se dice, jamás perdió una batalla.

En 1643 el jesuita Bolland se impuso la inmensa tarea de publicar la vida de los santos, siguiendo su orden en el calendario. Dedicó su vida a ello y la dejó inconclusa, pero fue terminada por recomendación de eruditas autoridades clericales y seglares.

La vida y la obra de Sor Juana son extremadamente disruptivas. Sus versos han tenido mayor repercusión que las acciones de cualquier virrey; aun los románticos mexicanos la tuvieron por cima de las letras, con todo y que detestaban el barroco. El soneto que dedica a Carlos de Sigüenza y Góngora ¿no es decisivo para entender la biografía de ella y de él? Y de las virreinas, tan poco conocidas, algo sabemos de ellas por los poemas que les dedica Sor Juana ${ }^{2}$ (Cruz, 1979, p. 377).

Voltaire escribió El siglo de Luis XIV (1751) y otros periodos históricos también se nombran por la figura política más destacada de la época: el siglo de Pericles, la era isabelina, la era victoriana. Sobre el siglo XviII se cuenta con investigaciones recientes de las biografías colectivas y la idea de la muerte de las elites, por ejemplo, el libro de Verónica Zárate Toscano (2000), Los nobles ante la muerte en México 1750-1850. Este tipo de trabajos enfocados desde la historia social tocan, de una manera diferente, la vieja costumbre de morir.

En el siglo xix el culto a los héroes llegó a equipararse con los nacionalismos. Así, Manuel José Quintana, escritor español, rinde homenaje al almirante Nelson, vencedor de la batalla naval de Trafalgar, muerto en ella por sangría de la femoral, como los antiguos toreros; dijo Quintana:

Terrible sombra

No esperes, no, cuando mi voz te nombra,

Que vil insulte a tu postrer suspiro:

Inglés te aborrecí, y héroe te admiro.

(Riva Palacio, 1979, p. 200).

\footnotetext{
${ }^{2}$ Algunos piensan que las obras en prosa son más dignas de crédito que la poesía, pero puede mentirse lo mismo en prosa que en verso. Ejemplo perfectamente fidedigno de historia escrita en verso es la Historia de la Nueva México (Pérez de Villagrá [1610] (1989).
}

\section{(ㅇ)(1) $\$$}


Con Ivanhoe (1820) Walter Scott inicia una revolución al crear la novela histórica propiamente dicha. En tiempos anteriores se habían historiado de manera literaria los tiempos pretéritos, pero lo que hace diferentes a Scott y a sus innumerables seguidores es que tienen una nueva manera distinta de comprender el pasado:

En todas las épocas se noveló el pasado pero fue especialmente en el periodo romántico cuando las novelas históricas aparecieron en constelación con una implícita filosofía de la vida. Los racionalistas habían desatendido las raíces históricas de la existencia. Cuando ofrecían asuntos lejanos apuntaban a lo inmutable; y la móvil relatividad y versatilidad del hombre se les escapaba. La filosofía romántica, en cambio, insistió en que vivimos en el tiempo y, por tanto, el sentido de nuestras acciones está condicionado por las particularidades del proceso cultural. El novelista del siglo xIX -el siglo de la historiaenriqueció, pues, el viejo arte de contar con un nuevo arte de comprender el pasado (Anderson, 1974, p. 93).

Los héroes de la independencia de México han tenido sus altas y sus bajas. A la apoteosis del triunfo insurgente siguió el desencanto de la ruina económica y política del país, de tal modo que esos héroes literalmente bajaron de su pedestal y se confundieron con los transeúntes. La excepción, en el Caribe, de esta tendencia de pasar de lo sublime a lo mundano, es el caso del cubano José Martí, quien murió en la primera batalla de la guerra de independencia (1895) y quedó, para siempre, héroe impoluto; por otra parte, dejó una obra escrita perdurable. A diferencia de Hidalgo que tuvo tiempo de cometer algunos errores en Guanajuato, en el Monte de la Cruces y en Guadalajara.

Durante mucho tiempo -ahora mismo- muchos personajes de nuestra historia han sufrido severas e inútiles reconvenciones; O'Gorman (1974) propuso otra actitud:

Desconocer las flaquezas de los héroes para hacer de ellos figurones acartonados que ya nada pueden comunicar al corazón; no conceder, en cambio, ni un ápice de buenas intenciones, de abnegación y patriotismo a hombres y mujeres eminentes que abrazaron causas históricamente equivocadas o perdidas; predicar, en suma, como evangelio patrio, un desarrollo histórico fatalmente predestinado al triunfo de una sucesión de hombres buenos sobre otra sucesión de hombres malos, no es sino claro eco de un tipo de naciona-

\section{(ㅇ)(1) $(2$}


lismo superado y dañino y cuya supervivencia revela una lamentable falta de madurez histórica (p. 32).

Nativo de Escocia y con sólidos estudios Thomas Carlyle (1957) convirtió en doctrina la larga tradición de escribir la biografía de las personas eminentes. ${ }^{3}$ La parte medular de su ensayo sobre Los héroes (1841) dice así:

For, as I take it, Universal History, the history of what man has accomplished in this world, is at bottom the History of the Great Men who have worked here. They were the leaders of men, this great ones; the modellers, patterns, and in a wide sense creators, of whatsoever the general mass of men contrived to do or to attain; all things that we see standing accomplished in the world are properly the outer material result, the practical realization and embodiment, of Thoughts that dwelt in the Great Men sent into the world: the soul of the whole world's history, it may justily be considered, were the history of these (p. 1).

Es interesante que Carlyle, al referirse a los grandes hombres, ponga especial énfasis en los pensamientos de esos que fueron enviados al mundo (la conciencia determina la vida) seguramente por una Providencia. También puede apreciarse que el biógrafo, para serlo verdaderamente, debe ser capaz de cautivar a su auditorio, debe ser muy buen escritor. La respuesta en Estados Unidos correspondió a Ralph Waldo Emerson en su famosa obra Los héroes representativos (1850). En él es notable la estirpe puritana en la que cada uno tiene su propia relación con Dios y comprobaba en el éxito económico (fomentado por el ahorro, la frugalidad) ser un individuo del buen pueblo elegido por Dios. Puritanismo este tan distinto a nuestros mayordomos que, en las fiestas, queman el dinero en pirotecnia. El plan divino se cumple, para Emerson (2015), cuando cada individuo, grande o no, asume su papel, su misión personalísima:

${ }^{3}$ Otra obra notable de Thomas Carlyle (2015) es Sartor Resartus. Christopher Domínguez (2004) la ha puesto de nuevo en circulación al utilizar fragmentos como epígrafes capitulares en su Vida de fray Servando.

\section{(ㄷ)(1) $\$$}


En el plan divino, la virtud penetra en el universo entero. Ningún hombre hay tan pobre que no participe de ella. A falta de opulencia, puede poseer la sabiduría; a falta de sabiduría la fuerza (p. 103).

[...]

Yo soy responsable de toda la sabiduría que saco de la sabiduría de Roma, de toda lección que me da la muerte de tantos héroes, de la decadencia de tantas naciones (p. 116).

[...]

La tentativa de realizar, de fijar un pensamiento, un principio fracasa continuamente. No se puede vivir sino para sí mismo; vuestra acción no vale sino en tanto que os es interior. La imitación torpe de vuestras acciones por vuestros hijos, por vuestros discípulos, no es la repetición, no es la misma cosa, sino una cosa nueva. A cada individuo le corresponde resolver por sí mismo el problema entero de la ciencia, de las letras, de la teología. No podría deber nada a sus padres; no hay historia, no hay más que biografía (pp. 259-260).

En México Carlyle fue recibido con entusiasmo por el romanticismo y todavía en 1882 Vicente Riva Palacio (1979) usaba sus conceptos para combatir al positivismo de corte spenceriano. Los argumentos del general son varios, entre ellos el siguiente:

La teoría del grande hombre no implica necesariamente la idea de que él ha creado los elementos sociales, sino de que él los amalgama, los combina, los aprovecha y los dirige en tal sentido, que producen una evolución inesperada, o que violentan la que debía venir; y en cualquiera de estos dos casos, es la influencia de aquel hombre la que se siente en la evolución y la historia de ella es la historia de él (p. 317).

Para muchos literatos de la época el romanticismo cotiza a la baja y el modernismo a la alta, pero debe recordarse que aquel en su tiempo fue sumamente rebelde y nos liberó del peso secular que venía desde la acrópolis de Atenas hasta el palacio de Versalles; después, fue mucho más fácil ser rebelde, como lo han sido todas las escuelas que vinieron más tarde.

Así como la teoría del grande hombre encaja perfectamente con el romanticismo igual lo hace con el capitalismo. A decir de Riva Palacio (1979):

\section{(ㅇ)(1) $(2$}


Y ahora, ¿podrá negarse que estos agrupamientos agrícolas, industriales, etc., despiertan, se mueven se organizan y se ponen en actividad por la iniciativa, el cálculo, la ciencia, la constancia o el atrevimiento de un hombre? ¿Será necesario poner ejemplos de esto en un siglo en que las sociedades anónimas, que nacen siempre de la idea de un solo hombre, están produciendo una inmensa evolución en todo el mundo civilizado? ¿Será necesario citar casos cuando apenas habrá individuo medianamente acomodado que no tenga parte o intervenga de alguna manera en una sociedad anónima, creada por la iniciativa de un solo hombre? (p. 316).

Otro aspecto importante para Riva Palacio es que los pueblos no deben de ser ingratos con quienes han dado lo mejor de sí para la existencia o la mejora del país. En otra obra, El libro rojo (1870), se refiere este autor, siempre conciliador, a Agustín de Iturbide y a su abuelo, Vicente Guerrero Saldaña, considerando a ambos libertadores de México (Riva Palacio, 1946, pp. 351-352).

Entre muchas obras notables mexicanas del siglo xix al menos debemos mencionar el Diccionario universal (1853-1856) que es la versión criolla de una obra chapetona y la más erudita Bibliografía del siglo xvI de García Icazbalceta que ve la luz hasta 1886 , con las biografías de los autores cuyos libros reseña. ${ }^{4}$

Tal vez el biógrafo más prolijo de nuestro siglo xix fue el campechano Francisco Sosa, quien escribió cerca de un millar de biografías breves que han sido plagiadas por muchos diccionarios biográficos. Fue también crítico literario y misógino feroz e irredento. Retrata sus límites en la biografía que escribe de Ignacio Ramírez (Sosa, 1996, p. 40) al referirse a vaguedades y omitir el cataclismo de 1836 ocurrido en la Academia de San Juan de Letrán, ${ }^{5}$ en donde el temerario Ramírez sostuvo la tesis de que "Dios no existe. Los seres naturales se sostienen por sí mismos”, antecedente remoto del Estado laico. Su Ilustrísima nunca perdonó al Nigromante: en vida Ramírez formó parte de la redacción de muchos periódicos, pero jamás publicó un libro. Como decían entonces: el clero tiene emisarios por todas partes. Aun si estamos de acuerdo con Plutarco, en el sentido de que deben disimularse los yerros de los

\footnotetext{
${ }^{4}$ Por cierto, hace mucha falta una bibliografía de biografías.

${ }^{5}$ Véase también Ortiz Monasterio (1991; 1996a).
}

\section{(ㅇ)(1) $(3$}


héroes, no es válido ocultar los pasajes decisivos para comprender al héroe. Gutiérrez Nájera despachó a Sosa en cuatro versos:

\author{
El Sol publica una cosa \\ En verso pluscuamperfecto \\ Y lleva la firma Sosa \\ $\mathrm{Y}$ en efecto, en efecto. \\ (Ortiz Monasterio, 1996a)
}

Utilizar la biografía como ciencia auxiliar de la historia siempre ha sido costumbre inveterada y viva. Esto puede comprobarse en las dos obras de mayor aliento de la época, una coordinada por Vicente Riva Palacio, México a través de los siglos (1884-1889), y la otra dirigida por Justo Sierra, México: su evolución social (1900). En esta última, en el capítulo titulado "La era actual", Justo Sierra combina la sociología con la biografía para desentrañar la "ecuación personal" del general Porfirio Díaz.

Las innumerables biografías que se escribieron sobre don Porfirio, cuando gobernaba -lo señaló Cosío Villegas- son casi todas panegíricas o, más precisamente, hagiografías; tal vez se salvan unas pocas. Con la llegada de la revolución se convirtieron en filípicas. Los años inciertos que vinieron después y la polarización política no eran campo fértil para los estudios históricos, pero hay rarezas, tal la biografía del cura liberal decimonónico Agustín Rivera, escrita por Mariano Azuela (1942). La autobiografía ${ }^{6}$ tuvo mucho éxito entre los generales de la revolución, en esa forma de rectificación de la historia para exagerar los méritos propios. En las Memorias de Gastón N. Santos (1984), el autor relata, de dos maneras diferentes y en distintas partes del libro, cómo conoció al presidente Ruiz Cortines; de modo que estas supuestas fuentes de primera mano no inspiran confianza. Jorge Ibargüengoitia (1994) escribió una deliciosa sátira de este género titulada Los relámpagos de agosto.

Una manera muy especial de entender al hombre y su circunstancia fue la que defendió el filósofo español Ortega y Gasset. Una vida -dice- no

\footnotetext{
${ }^{6}$ Entre los historiadores que escribieron autobiografías está Gibbon (1949) y, escrita en tercera persona, Vico (1970). Más recientes son las autobiografías de Luis Cardosa y Aragón (1986), y Luis Buñuel (1982). Este último asegura que lo decisivo es en compañía de quién mueres, supongo que quiere decir los familiares, los amigos que quedan.
}

\title{
()(1) $\$$
}


puede comprenderse en forma individual sino conociendo también lo que hicieron los coetáneos: "La historia no se ocupa de tal vida individual; aun en el caso de que el historiador se proponga hacer una biografía, encuentra a la vida de su personaje trabada con las vidas de otros hombres y la de estos, a su vez, con otros; es decir, que cada vida está sumergida en una determinada circunstancia de una vida colectiva" (Martín, 2008).

Para Ortega y Gasset cada generación estaba separada por 25 años, de modo que en cualquier momento podían coexistir tres generaciones.

Entre nosotros el enfoque generacional ha sido muy socorrido. Se le encuentra con mucha frecuencia entre los estudiosos de la literatura. Entre los mexicanos que estudian las generaciones es obligado mencionar a Luis González y González (1984), quien tiene la cortesía de ocultar su privilegiada inteligencia detrás de un lenguaje de todos los días. Sus panoramas generacionales, sin cuadros ni cifras, son óptimos.

Por otro lado, fuera de la academia, se han publicado biografías muy valiosas por verdaderos conocedores de la historia y de la política mexicanas, por ejemplo, los tres tomos sobre El liberalismo mexicano de Jesús Reyes Heroles (1982), la biografía del presidente Ruiz Cortines de Miguel Alemán Velasco $^{7}$ (1998) y la biografía de Santa Anna de Enrique González Pedrero (1993). Porque es muy fácil corregirle la plana, a toro pasado, a todos los personajes de la historia, pero ¿en verdad sabemos tanto de realpolitik? Decimos cosas desde la comodidad de nuestro estudio: Cortés no debió salir de Tenochtitlan, la educación que impartían los jesuitas era nada porque eran curas, Iturbide perdió en Padilla debido a los mosquitos, el muralismo es la representación artística más importante desde las cuevas de Altamira.

Además, hay un tipo de biografía que utiliza la ficción muy moderadamente, sólo para llenar los intersticios entre los hechos, ajena a la academia pero que es un prodigio, me refiero a la biografía escrita por Alejandro Sobarzo (2012) donde demuestra que Trist, el negociador estadunidense del Tratado de Guadalupe no fue un ogro, sino un caballero. Esta obra tiene además el mérito de ocuparse de la historia de otros países, Cuba y Estados Unidos. Y está muy bien escrita.

Un aspecto muy favorable del siglo $\mathrm{xx}$ fue el inicio de la globalización de los estudios históricos. Con los antecedentes ilustres de Prescott y Ban-

${ }^{7}$ Esta obra vale mucho en la medida de que el hijo del presidente Miguel Alemán Valdés no oculta su lugar de privilegio.

\section{()(1) $\$$}


croft un nutrido contingente de historiadores extranjeros, muchos de ellos biógrafos, en su mayoría estadunidenses pero también ingleses y franceses, nos permitieron entablar un diálogo de altura. El método sistemático y bien documentado de estas obras ha permitido que tengan, en muchos aspectos, vigencia hasta nuestros días, ejemplo de ello es la biografía que escribió William Spence Robertson (2012) sobre Iturbide, publicada en inglés en 1953 y luego traducida. Hay también biografías cuyo enfoque es el de otras disciplinas, como es el caso de la obra del antropólogo Oscar Lewis (1963), The children of Sánchez.

La biografía, la historia toda, es un bien mostrenco al alcance de todos los que puedan escribirla, por más que esto sea para algunos inaceptables. La tolerancia es precisa aun cuando haya biografías que utilizan el componente de ficción para fines porno, como es el caso de la del cubano Reinaldo Arenas (1978). Los excesos de la libertad deben tolerarse para que haya cierto grado de libertad, porque hay todo tipo de candados y escollos en el camino y son muy pocos los que pueden decir: planté un árbol, tuve un hijo, escribí un libro.

La renovación que representó la escuela de los Annales en Francia, la cual se oponía a la "historia batalla" y privilegiaba la historia económica y social, no dejó fuera de su proyecto a la biografía. El propio Lucien Febvre (1956), uno de los fundadores de la escuela, escribió la de Martín Lutero: un destino.

En la segunda mitad del siglo xx, en Estados Unidos, Francia e Inglaterra, se hicieron investigaciones históricas utilizando el método de la prosopografía, es decir biografías colectivas. Stone (1986) define la práctica de este enfoque: "La prosopografía es la investigación retrospectiva de las características comunes a un grupo de protagonistas históricos, mediante un estudio colectivo de sus vidas. El método que se emplea es establecer un universo de análisis, y luego formular una serie uniforme de preguntas" (p. 61).

Originalmente se creó como una herramienta de la historia política, pero también ha sido usada por la historia social; al principio se usó lápiz y papel, después computadoras.

Precursor del uso de la computadora en el campo de la prosopografía de tema mexicano fue François-Xavier Guerra (1998) con su México: del antiguo régimen a la revolución. Esta obra es de gran interés porque estudia dos periodos que se consideran antitéticos: el porfiriato y la revolución de 1910. En la medida en que periodizar es una forma decisiva de interpretación la obra de Guerra es fuera de serie y muestra que la ruptura que siempre se atribuye a

\section{()(1) $(9$}


esa revolución, debe ponderarse por los muchos rasgos que tuvo de continuidad. Hubo quien rechazara las investigaciones de Guerra, como fue el caso del maestro Moisés González Navarro (1987). Hasta la fecha se discute qué aportó el general Porfirio Díaz y cada quien responde con su verdad desde su "lugar social", según la expresión de Michel de Certeau (1987).

José Luis Martínez (1993) escribió un libro que marcó y liberó a varias generaciones, me refiero a La expresión nacional que contiene mucha información biográfica. En esa época el canon había dejado fuera a autores necesarios, especialmente a los románticos. Es difícil aquilatar ahora las agallas que requirió escribir ese libro, en un tiempo en que las capillas, como los conventos coloniales, remataban con almenas en el caso que se necesitaran. También escribió una buena biografía de Hernán Cortés (Martínez, 1990) que llamaba, con rigor y amplio fundamento documental, a una reconciliación con nuestro pasado. Sus estudios de tema prehispánico, especialmente el que dedicó a Netzahuacóyotl (Martínez, 1986), dejaban a las claras que, del periodo prehispánico y el periodo colonial de nuestra historia, bien podía decirse lo mismo que se dijo de los reyes católicos "Tanto monta, monta tanto, Isabel como Fernando". Adicionalmente el maestro José Luis Martínez publicó, en varios volúmenes, lo esencial de los documentos cortesianos.

El reverso de la medalla de la biografía como ciencia auxiliar de la historia, que aspira a lo general, es el concepto de la biografía literaria que propuso Marcel Schowb (1922):

El arte está en oposición con las ideas generales, no describe sino lo individual, no desea sino lo único. No clasifica; desclasifica. [...] Las ideas de los grandes hombres son el patrimonio común de la humanidad: cada uno de ellos sólo es dueño realmente de sus singularidades. El libro que describiese un hombre en todas sus anomalías sería una obra de arte, como una estampa japonesa en la que se ve eternamente la imagen de una pequeña oruga percibida una vez a una hora particular del día (pp. 16-17).

Creo que esta idea del género biográfico, la versión literaria llevada hasta el extremo, es poco común entre nosotros. Tal vez entre en esta categoría Farabeuf, de Salvador Elizondo (1965). Los más entre los autores de novelas históricas y biografías noveladas prefieren aprovechar la ambigüedad de si es o no es verdad histórica, y usan la ficción en el sentido de fingir, mentir, y no en el más interesante de fabricar. La verdad histórica no es analizada como

\section{()(1) $(9$}


un problema epistemológico sino como un capitalito del que no hay que desprenderse, para poder así llamarse literatos o historiadores según convenga.

En cuanto a la biografía histórica actual requiere de una reflexión importante, lo mismo que cualquier otro género historiográfico. Se ha superado la ingenuidad de otros tiempos e historia y literatura son dos vertientes de un único propósito. François Dosse (2007) señala:

La biografía participa, así, en el giro interpretativo adoptado por los trabajos históricos actuales y confirma la necesidad de no dejarse acorralar en la fase alternativa entre una cientificidad que remitiría a un esquema monocausal organizador y una variación embellecedora. La operación historiográfica, para retomar la expresión de Michel de Certau, es una operación compleja, mixta, que hace que cualquier objetivismo sea caduco, lo que no quiere decir que por eso se rompa con la esfera que para ella constituye desde siempre un contrato de verdad que debe revelarse. "Es una mezcla, ciencia-ficción, cuyo relato es razonamiento sólo en apariencia, pero no por ello está menos circunscrito a los controles y a las posibilidades de falsificaciones" (p. 431).

Para Certeau no existe sitio desde donde pueda enunciarse "la verdad", incluso desde la academia, que produce un discurso con pretensiones de "verdad", encontramos sutiles lazos con el Estado. La academia, en su mejor forma, debe trabajar en los márgenes del Estado; su opuesto serían los estatutos de los partidos políticos, enunciados desde el centro del Estado. La ficción se introduce de manera sutil en el discurso histórico, por ejemplo, cuando se trabaja masivamente con la computadora el técnico cree que los datos que le proporciona el historiador son "la verdad", en tanto que el historiador piensa que la tecnología le permite construir una "verdad".

\section{EXPERIENCIAS PERSONALES}

\section{El Diccionario Porrúa}

Habiendo tenido a su cargo, primero el padre Ángel María Garibay y después Felipe Teixedor, las primeras ediciones, la quinta edición del Diccionario Porrúa (1994) se realizó bajo la dirección de Miguel León-Portilla. Alejandra Lajous Vargas y el que suscribe formamos un equipo de jóvenes historiadores

\section{()(1) $\$$}


para corregir y aumentar las cédulas, principalmente las biográficas, del Diccionario Porrúa correspondientes al siglo $\mathrm{xx}$, que era la etapa de nuestra responsabilidad. Recuerdo que visitamos a don José C. Valadés quien había advertido errores en ediciones anteriores del Diccionario Porrúa y nos conminó a corregirlos para que, en sus palabras, no quedaran "para toda la eternidad".

Las cédulas del Diccionario Porrúa no vienen firmadas, pero en lugar aparte viene una larga lista de los principales colaboradores. La antigüedad de la obra (la primera edición data de 1964) refleja el empirismo de la historiografía de la época, que para una obra de este tipo no estorba, partiendo de los siguientes principios para las biografías: reunir hechos consumados (todos los biografiados habían fallecido); se dan los datos con la mayor objetividad posible; se propone una solución para los errores que resistieron a la diligencia que se procuró: "La editorial ve con agrado toda comunicación referente a equivocaciones, deficiencias omisiones, y acaso aun errores de las cédulas que se ofrecen" (Diccionario Porrúa, 1994, p. x).

Identificamos las entradas ya existentes correspondientes al siglo $\mathrm{xx}$. En seguida hicimos una lista de ellas que permitió advertir fácilmente lo faltante; se investigaron y redactaron las nuevas biografías, siguiendo siempre el formato y las abreviaturas de las cédulas existentes.

En la quinta edición del Diccionario Porrúa se logró aumentar un tomo más para sumar tres; en su mayor parte las nuevas cédulas corresponden al siglo xx. Los hermanos Porrúa insistieron en editar el Diccionario Porrúa siguiendo el método tradicional, cortando y pegando los negativos, a pesar de que ya se vislumbraba la era digital.

\section{El Diccionario del gobierno mexicano}

Este diccionario da a conocer la trayectoria de los principales servidores públicos del poder ejecutivo, del poder judicial y del poder legislativo. Suma 1948 biografías confeccionadas por los propios funcionarios en respuesta a los cuestionarios que preparé para tal efecto. Así, la información es coherente y homogénea; va más allá del curriculum vitae al incluir en el cuestionario información interesante, por ejemplo, sobre la profesión del padre y de la madre, útil para medir la movilidad social.

Para elaborar el cuestionario revisé el libro fundador de Roderic Ai Camp (1976), pero él jamás imaginó el detalle y la amplitud de información

\section{(이) $(9$}


que una fuente oficial llegaría a aportar. La limitación de este diccionario es que informa sobre carreras en proceso de funcionarios que, en su mayoría, no habían terminado aún su labor; se trata de un corte a la fecha del 1 de mayo de 1984.

\section{Prosopografía}

El propósito fundamental de la prosopografía es reunir una constelación de personajes que aquilatados y comparados pueden dar luz sobre una profesión, un grupo político o una generación literaria. Casi siempre son universos de elites, pues son estas las que con más frecuencia pueden documentarse. Por ejemplo, hice una investigación sobre los médicos mexicanos del siglo XIX para indagar cuántos de ellos, quiénes, de qué forma, durante cuánto tiempo y con qué resultados ocuparon cargos políticos (Ortiz Monasterio, 2004, pp. 35-50). Dejando de lado a los que ocuparon gubernaturas, así como otros cargos políticos menores, destacan: Anastasio Bustamante, quien fue presidente de México, Valentín Gómez Farías, vicepresidente, y Lorenzo de Zavala, vicepresidente de la república de $\operatorname{Texas}^{8}$ (Ortiz Monasterio, 2004). El principio constitucional de libertad de trabajo del siglo xIX permitía el ejercicio de la medicina a todo el mundo y había charlatanes por doquier. Pero además la charlatanería se justificaba porque en Sonora, por ejemplo, a principios del siglo XIX no había un solo médico graduado (Ortiz Monasterio, 1993b).

Otra forma prosopográfica, por así decirlo previa, es cuestionar si la constelación que se elige realmente constituye una profesión. Con los escritores mexicanos del siglo xIx ocurre que, estrictamente hablando, no constituían una profesión y se ganaban la vida escribiendo para los periódicos y en cargos políticos. Una de las cosas que encontré es que los maestros de esgrima pagaban impuestos, pero los escritores, más humildes, no los pagaban. Eso tiene su razón: en el momento de un duelo no vienen al caso las coplas. Mi conclusión fue la siguiente:

${ }^{8}$ Zavala aprendió medicina con un par de libros que le proporcionaron durante su prisión en San Juan de Ulúa. 
Creo que podemos convenir, según el examen que les he presentado, que desde el punto de vista social y profesional la literatura fue en el siglo xix una actividad marginal, que no llegó a ser una profesión propiamente dicha. No quiero decir que no haya sido importante para la construcción del México independiente, más bien me inclino a creer que la importancia enorme de la literatura aún no es debidamente apreciada por los historiadores; pero en cuanto profesión, estrictamente hablando, no logró en el siglo xIx consolidarse como tal (Ortiz Monasterio, 1996b, p. 331).

\section{Los ministros de Hacienda y sus proyectos}

En el libro coordinado por Leonor Ludlow (2002) para analizar a los ministros de Hacienda desde 1821 hasta 1933, se les estudia bajo el enfoque, se adivinará, de la historia económica. Tuve en suerte ocuparme del ministro liberal moderado Mariano Riva Palacio, padre del general yerno del libertador Vicente Guerrero, quien enfrentó la desolación del erario en los tiempos duros de la guerra contra Estados Unidos (Ortiz Monasterio, 2002, pp. 229-246).

Don Mariano es recordado por su tenaz defensa del archiduque Maximiliano, en el proceso o juicio sumario que se le siguió en Querétaro; en el Estado de México también es reconocido pues fue gobernador de esa entidad durante tres periodos. Pero se extraña, se extraña mucho, una biografía cabal, toda vez que Jack Autrey Dabbs (1967) publicó una guía, pormenorizada como ya no las hay, de su archivo personal que se guarda en la Universidad de Texas en Austin.

Como ministro de Hacienda del presidente José Joaquín de Herrera (hombre honorabilísimo) don Mariano enfrentó la difícil tarea de cuidar la indemnización de 15000000 de pesos, para que este ingreso extraordinario con el que los estadunidenses pagaban la anexión del territorio no se perdiera en gastos de poca trascendencia. Ellos no sabían que la voracidad del enemigo estaba saciada, por lo cual se gastó mucho en el ejército que defendía el norte. Los pagos atrasados de los empleados fueron la otra sangría del cuerpo de los millones, por más que don Mariano intentó ponerle coto.

La principal virtud de esta obra es el análisis de larga duración de la Hacienda que, analizada a partir de la biografía de los ministros del ramo, queda a la disposición del estudioso de las biografías colectivas. Esta obra incluye además un gran número de cuadros, leyes y reglamentos.

\section{()(1) $\$$}




\title{
Biografía literaria
}

Dentro de la colección "Charlas de café con..." contribuí con la biografía de Vicente Guerrero Saldaña, que debía ser breve y literaria. La acción tiene lugar en un Cielo que se parece mucho a una laguna de la Costa Chica, inmediata al mar Pacífico. La forma es un diálogo entre Guerrero y el de la voz. De entrada, enfrenté un escollo de consideración: no encontré ninguna biografía digna de tal nombre de Guerrero, prueba de que en nuestra historiografía no hay lagunas sino mares. Sin embargo, percibí que el enfoque literario permitía extrapolar información de otras fuentes históricas, tal la visita que hizo el general Michelena a Tierra Santa, de donde trajo el primer café que aquí se conoció; tal la peculiar capa dura del coco en que se bebía el chocolate, que había yo visto en el Museo Regional de Chilpancingo; tal el papel de correos que cumplían los arrieros a principios del xIx.

Pero me resultaron aún más útiles mis experiencias personales que permitían un relato más suelto y vívido o, como decían antes, esas experiencias le dan a cualquier trabajo literario un colorido de verdad, a través de la descripción de los detalles más exactos. Entre otras mercancías los arrieros transportaban ganado y me fui muy útil ver cómo se conducía en Bahía de Banderas un toro Brahman casi adulto, y en consecuencia temible, por un hombre a caballo que me decía "no te agüazapes"; o el comentario, casi imperceptible, donde señalo que al subir a una embarcación pequeña el peso del que la aborda debe caer al centro de la canoa; o el gusto de mi generación por la música tradicional, lo que me llevó a improvisar ciertas coplas algo picantes, en fáciles octosílabos:

\author{
No le tengo miedo al miedo \\ sino al baile de esta chica \\ en este Cielo me quedo \\ ique viva la Costa Chica! \\ (Ortiz Monasterio, 2009, p. 26).
}

Las escenas, las palabras subiditas de color, se justifican porque dan verosimilitud al relato, pero, especialmente, es mi opinión, para decirle a su majestad el lector que no lo hemos olvidado, que sus deseos son órdenes. Tal vez este no debe ser el criterio que debe seguirse en una elevada obra literaria,

\section{(1)(1)}


pero me considero historiador y me basta una prosa animada. En otra parte también doy prioridad al lector con un párrafo que no es invento mío:

\section{[Yo:] ¿Conoció usted a la Güera [Rodríguez]?}

[Guerrero:] No en el sentido bíblico, profesor. Era una bella dama de alcurnia de la capital y decidida partidaria de la Independencia. Es lástima que hoy no se recuerden sus servicios al país pero sí, en cambio, que fue amante de Simón Bolívar, del barón de Humboldt, de Agustín de Iturbide y, se sospecha, también de su marido (Ortiz Monasterio, 2009, p. 71).

La ventaja de este texto es que su lectura es amena, la desventaja que hay demasiadas fechas y datos históricos que se pudieron haber quitado y eso que dejé pocas.

\section{Biografía literaria contrafactual}

La historia contrafactual ha sido primero imaginada y luego cuantificada por historiadores estadunidenses quienes, para medir el impacto de los ferrocarriles en su país observaron al otro: ¿qué hubiera pasado si en lugar de ferrocarriles se hubiera construido una amplia red de canales desde el Mississippi y el Ohio?

La hipótesis de que Zapata no murió en Chinameca es, para la historiografía al uso, contrafactual, pero no lo es desde la perspectiva literaria que puede tener su propio faro, que era lo que me pedían los editores de El libro rojo. Se privilegiaba la verosimilitud, antes que la "verdad" histórica (Ortiz Monasterio, 2008).

Yo cuestioné, reitero, si Emiliano Zapata en efecto había muerto en Chinameca. Todo empezó en un paseo por el convento del hospital donde los viejos del lugar me aseguraron que Zapata no había muerto como se cree, sino que dejó las armas y partió a Italia o, según otros, a Turquía o a Arabia, tierra de óptimos caballos.

Fui encontrando, al estudiar la muerte del caudillo, muchas rarezas. El documento principal que da fe de la muerte de Emiliano Zapata es la fotografía famosa que le tomaron al cadáver en Cuautla; mas esa cara abotagada bien pudo ser la de un primo o un compadre. Lo más extraño es que el exza-

\section{(ㄷ)(1) $\$$}


patista que reconoció in situ al muerto fue fusilado cuatro días después por los carrancistas, ¿ipor qué fusilaron a tan importante testigo?

El parte oficial zapatista, escrito el mismo día del trágico suceso por el mayor Salvador Reyes Avilés, en el que se informa del acontecimiento, es extrañísimo. Está escrito con fracasados pero laboriosos vuelos literarios y viene acompañado de muchas cartas y documentos probatorios. Es más lógico pensar que tamaña noticia se escribiera en cualquier papel en la cabeza de la silla y se entregara a todo galope. Pudo haber sido de otra manera, pero el parte oficial me parece que es un fingido lamento, no expresa la conmoción del primer duelo.

Un gallo tan jugado como Zapata jamás se hubiera presentado con unos pocos hombres en la hacienda de Chinameca para enfrentar a Guajardo, el enemigo de ayer que fingidamente se ponía a las órdenes del caudillo del Sur. Este cuidaba mucho de lo que se daba de comer y tenía preferencia por el atole confeccionado frente a sus ojos. ¿Tantos años de campaña, esquivando mil peligros para caer en una celada que él mismo fue a encontrar?

El porqué del exilio de Zapata es una tradición (leyenda), pero puede explicarse si se considera que la revolución zapatista acusa características muy propias. Era de gran peligrosidad pues la guerra llegaba hasta las goteras de la capital, ya por la vía llana de Cuautla o bien por la ruta montañosa de Topilejo, Tlalpan y San Ángel. Por otro lado, a diferencia de otras regiones, la tierra y el agua ya habían sido repartidas en Morelos, que era la principal reivindicación de aquel primer zapatismo. ¿Hubo un pacto que ratificaba ese reparto agrario, a condición de que Zapata saliera del país? Es decir, jaque, pero no mate.

Mi texto sobre Zapata da cuenta de una investigación que hice para fines literarios que alcanzara la verosimilitud, pero se convirtió en un escrito de dudoso género híbrido. En la vieja cuestión de la verdad, que discutir en serio es harina de otro costal, debe considerarse que un texto historiográfico no puede siempre distinguirse de otro literario: no son de diferente color o sabor, o aun de estilo, que a las claras los haga distintos. Una cita directa o una nota al pie forman parte del estilo historiográfico, pero por diversas razones no son verdades irrefragables ni el aparato crítico ni la aparente erudición.

En este plano, completamente literario, bien puede decirse que los viejos de Anenecuilco conminaron al bravo Emiliano para que depusiera las armas y partiera a Arabia, donde el Califa lo tendría como caballerizo mayor; por las noches reposaría en su serrallo.

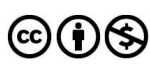




\section{Una biografía general}

Un verano en la Universidad de Texas en Austin (y años de investigación preliminar) fue bastante para documentar la vida de Vicente Riva Palacio. Treinta mil documentos; pero conté con la ayuda invaluable de la guía inédita de ese archivo (existe una copia en la biblioteca del Instituto Mora) elaborada por Jack Autrey Dabbs, finado. Conocí a la viuda quien me dio acceso a la guía y me mostró su poema "The tiger", sobre el cual comenté que era un tigre agazapado que, lenta y extrañamente, se queda dormido; entablamos amistad.

La otra colaboradora fue la fotocopiadora, literalmente a tres pasos del escritorio que yo ocupaba, que me brindó el auxilio de sus luces; al oscurecer yo verificaba que no faltara ninguna foja en los documentos fotocopiados. En consecuencia, la principal dificultad para escribir la biografía de Riva Palacio fue el exceso de información; el caso contrario es el más común. Adicionalmente, para la publicación, tuve que trabajar a paso veloz: el compromiso con el Consejo Nacional para la Cultura y las Artes era entregar la biografía en seis meses; a veces los plazos son freno, otras veces acicate. No se trata de una biografía general, en el sentido de que se ocupe de todos los actos y todas las obras del personaje; es solo una biografía que sin duda puede mejorarse. Lo más interesante de este proyecto fue que la colección originalmente imaginada por el Consejo Nacional para la Cultura y las Artes resultó desigual, no pudo publicarse completa porque cada autor tenía su propia idea de lo que era una biografía. Las había breves y literarias, otras medianitas sin notas ni bibliografía y muy pocas pretendieron ser históricas, extensas y profusamente anotadas. ¿Qué es una biografía? Es una pregunta que tiene muchas respuestas.

¿En qué medida se identifica el biógrafo con el héroe? En mi caso muchísimo. Mi maestro Lothar Knaut lo llamaría una experiencia vicaria. Escribir una biografía es, insisto que en mi caso, una forma de complicidad entrañable que busca poner en valor la vida y la obra del héroe. Es cierto que se establece un diálogo, pero con la ventaja de que el otro está muerto; cierto se hacen numerosas citas textuales, pero el ventrílocuo se considera el mandamás que quiere hacer creer que, en efecto, hay un diálogo. Pero cualquier trabajo mío (y sospecho que no estoy solo) más se parece a una fabricación y a un acto de imaginación que a una deducción, retrato fiel de los documentos. Edmundo O’Gorman relataba el caso de un libro que había leído donde

\section{()(1) $(2$}


el autor se jactaba de que todo lo que decía estaba basado en documentos, mejor hubiera sido -decía don Edmundo- que publicara los documentos, en vista de que nada aporta él. Respeto otras posibilidades, pero para mí la interpretación es de preferencia una transfiguración como la que apunta el título de la primera novela de Riva Palacio (1997): Calvario y Tabor, luego viene el laborioso trabajo de comprobar y componer la hipótesis. El Tabor es un episodio bíblico donde Cristo se presenta, transfigurado, ante los apóstoles. Así México, con el triunfo de 1867 se transfigura, muere la opción monárquica, fenece definitivamente la Nueva España.

He escrito otros dos libros sobre la obra de Riva Palacio: Historia y ficción. Los dramas y novelas de Vicente Riva Palacio (1993a) y México eternamente. Vicente Riva Palacio ante la escritura de la historia (2004). El primero está escrito con un flujo natural que tal vez he perdido. El segundo cumple mi objetivo de origen -comprender la obra historiográfica de Riva Palacio-. En ambos hay información biográfica original. Además, los textos escritos por el general Riva Palacio son ricos y variados, sin duda fuentes indispensables en el caso de las biografías de escritores, como lo fue el general. Edité también las Obras escogidas de Vicente Riva Palacio en 16 volúmenes (1996-2006), para lo cual invité a diversos académicos a hacer los respectivos prólogos; con alguna intervención importante de mi parte creo que la multiplicidad de lecturas fue una opción atinada.

En ese primer libro mío, Historia y ficción (1993a), utilicé como parapeto la advertencia de que yo analizaría los dramas y novelas de Riva Palacio en lo que tenían de histórico, no de literario. Pero más tarde comprendí que no es posible hacer una distinción precisa de historia y literatura, que se explican mejor como vasos comunicantes. En consecuencia es preciso que el historiador que se ocupa de un escritor se acerque a los críticos literarios, participe en sus seminarios, se atreva en sus congresos. Hallar un lenguaje común no es tan arduo tratándose de disciplinas que son primas hermanas, por decir lo menos. Lo estético no es inasequible para el historiador. Posiblemente yo me quedé corto, pero me afané.

La biografía también sirve para obtener interpretaciones más generales. La apreciación de la época en cuestión, sobre la cual se podrían reunir fácilmente un millón de documentos, se beneficia por una cala profunda, un destino individual (lo particular), que se sigue pormenorizadamente y que aun sabiendo que el resultado será inacabado, y seguramente parcial, cada nuevo documento, cada momento de inspiración creadora provocan

\section{(1)(1) $\$$}


efectos siempre recomendables. Creo que ese es precisamente el objetivo de la biografía, entender una época sin olvidar a los hombres de carne y hueso que hicieron contribuciones importantes al país, en la guerra y en la paz. La interpretación que hace Riva Palacio de una historia integral que valora a Cuauhtémoc tanto como al Cid, es decir la interpretación mestiza de nuestra historia me parece una contribución fundamental.

Se me llamará monotemático o cuando menos exagerado por haber dedicado tanto tiempo -no todo- a reconstruir la biografía de un solo hombre; por lo mismo he llegado a pensar que, si hay una documentación y una obra con qué trabajar, se puede dedicar una vida entera a escribir una biografía y quedarse corto.

Por otro lado, los vínculos del biógrafo aparecen por todas partes. No sólo sus filias y fobias sino el "lugar social", diría Michel de Certeau, que ocupa. Mi formación en la Facultad de Filosofía y Letras de la UNAM, también en la Universidad Iberoamericana son perceptibles. Lo mismo mis orígenes familiares, mis gustos literarios y mi predilección por la historia de la historiografía y la teoría de la historia; incluso un hallazgo casual en una librería de viejo, cuando yo trabajaba en la Secretaría de Educación Pública. Vínculos no son vagos lazos; etimológicamente significan cadenas. ${ }^{9}$

\section{Antología de Sérgio Buarque de Holanda}

Es buena costumbre, en toda antología (Buarque de Holanda, 2007), hacer una introducción que permita conocer la biografía del autor. Esta tarea llega a ser ingente cuando se trata de un extranjero que escribió en otra lengua $y$, en consecuencia, es poco conocido en Hispanoamérica. En consecuencia, debe explicarse el contexto en el que vivió el personaje pues de otro modo no puede distinguirse lo pertinente de lo que no lo es, lo personal de lo social. Además, deben hacerse algunas aclaraciones sobre aspectos que pueden causar confusión, por ejemplo, el término "modernismo" que en Brasil puede fecharse a partir de 1922 y no tiene relación alguna con el "modernismo" hispanoamericano.

Lo que más admira de la literatura brasileña del siglo xx es que, desde el punto de vista mexicano, la búsqueda de una literatura propia es tardía,

${ }^{9}$ En Roma pude ver el San Pedro in vincoli, de Miguel Ángel, y las cadenas que le atan.

\section{()ㅜ(1) $\$$}


pero tiene un vigor muy considerable. Tal vez esto se deba a que nosotros estamos anclados en una rica cultura secular, en tanto que en Brasil lo que más interesa es el futuro: aquí el jarabe tapatío, allá la samba. $\mathrm{O}$, por decirlo en términos académicos, los eruditos brasileños tienen en poco su pasado; el mundo indígena les parece primitivo, el dominio portugués de poca monta: "Por exemplo, sem ignorar o papel do Infante Dom Henrique (1394-1460) e sua legendaria Escola de Sagres no incentivo à expansâo, hoje nâo se acredita que esses fatos tenham sido tâo relevantes quanto se pensaba até algunos anos atrás" (Fausto, 1999, p. 20).

Algunos procesos fundamentales tienen otra lógica allá. Durante el siglo XIX Brasil fue gobernado por monarcas de origen portugués pero el país había alcanzado la independencia desde 1822; en 1888 se da la abolición de la esclavitud y la república se establece en 1889 . En contraste con la modernidad que en el siglo xx se observa en Brasil, primero en el ámbito del conocimiento y después por todas partes.

Si Borges quería definirse no por los libros que había escrito sino por los que había leído, bien puede trazarse el perfil de Buarque de Holanda a partir de su biblioteca, que suma más de 8000 libros y supera los 200 títulos de publicaciones periódicas, así como 600 obras raras (siglo xIX y anteriores). Seguramente Buarque tuvo varias bibliotecas y esta es reflejo de lo que el autor quiso guardar al final de su vida. Es la Universidad de Campinas la que resguarda la biblioteca y el archivo personal del célebre paulista, perfectamente organizados. Hay una sección especial de artículos sobre don Sérgio, conservados originalmente por su viuda, de señalada utilidad.

El archivo de la colección Sérgio Buarque de Holanda también conserva numerosas fotografías; pedir reproducciones y solicitar permiso para su publicación fue un proceso muy ágil, como lo fue también el proceso de xerocar (fotocopiar) muchos textos.

\section{REFLEXIÓN FINAL}

Mi trayectoria profesional, como se ha visto, casi siempre ha estado cerca de los estudios biográficos. Lo anterior lleva a preguntarme ¿qué es un biógrafo? Es un escritor mirón que le interesa lo particular, solidario con los hombres y mujeres del pasado que pretende poner en valor, con cierto toque moral del que es difícil escapar. También es un científico que busca, mediante los

\section{(ㅇ)(1) $(9$}


estudios biográficos y en el universo colectivo de la academia, hallar verdades -más exactamente un discurso con pretensiones de verdad-con sabor a carne humana.

\section{LISTA DE REFERENCIAS}

Alemán Velasco, M. (1998). No siembro para mí: biografía de Adolfo Ruiz Cortines. México: Diana.

Anderson Imbert, E. (1974). El telar de una novela histórica. Enriquillo de Galván. En E. Anderson Imbert, Estudios sobre letras hispánicas. México: Editorial Libros de México.

Arenas, R. (1978). Un mundo alucinante: una novela de aventuras. México: Diógenes.

Azuela, M. (1942). El padre don Agustín Rivera. México: Ediciones Botas.

Bernal, M. (1987). Black Athena. The Afroasiatic Roots of Classical Civilization. Londres: Free Association Books.

Buarque de Holanda, S. (2007). Historia y literatura. Antología (selección e introd. de J. Ortiz Monasterio, trad. de A. Cisneros). México: Fondo de Cultura Económica/ Instituto Mora.

Buñuel, L. (1982). Mi último suspiro (Memorias). México: Plaza y Janes.

Camp, R. A. (1976). Mexican political biographies. Tucson: University of Arizona.

Cardosa y Aragón, L. (1986). El río. México: Fondo de Cultura Económica.

Carlyle, T. (1957). On heroes, heroe-worship and the heroic in history. Oxford: Oxford University Press.

Carlyle, T. (2015). Sartor Resartus (trad. E. González Blanco). Madrid: Bilok.

Certau, M. de (1987). La historia, ciencia y ficción. Historias, 16, 19-33. Recuperado de http://www.estudioshistoricos.inah.gob.mx/revistaHistorias/wp-content/ uploads/historias_16_19-34.pdf

Cruz, J. I. de la (1979). Florilegio. Poesía. Teatro. Prosa (selec. y pról. E. Trabulse). México: Promexa.

Dabbs, J. A. (1967). The Mariano Riva Palacio archives. México: Editorial Jus.

Diccionario Porrúa de historia, biografía y geografía de México (1994). México: Editorial Porrúa.

Domínguez Michael, C. (2004). Vida de fray Servando. México: Ediciones Era/Consejo Nacional para la Cultura y las Artes.

Dosse, F. (2007). El arte de la biografía. México: Universidad Iberoamericana.

Elizondo, S. (1965). Farabeuf, o la crónica de un instante. México: Joaquín Mortiz.

\section{()ㅜ(1) $\$$}


Emerson, R. W. (2015). Diario íntimo (trad. de Luis de Terán). Madrid: Desván de Hanta.

Fausto, B. (1999). Historia do Brasil. São Paulo: Editora da Universidade de São Paulo/ Fundação para o Desenvolvimento da Educação.

Febvre, L. (1956). Martín Lutero: un destino (trad. de T. Segovia). México: Fondo de Cultura Económica.

Gilgamesh o la angustia por la muerte (poema babilonio) [trad. directa del acadio, introd. y notas J. Silva Castillo]. (2016). México: El Colegio de México.

González y González, L. (1984). La ronda de las generaciones. México: Secretaría de Educación Pública.

González Navarro, M. (1987). La guerra y la paz o un nuevo refuerzo francés a la derecha mexicana. Secuencia, 7, 57-69. Dor: http://dx.doi.org/10.18234/secuencia. v0i07.165

González Pedrero, E. (1993). País de un solo hombre: el México de Santa Anna (3 vols.). México: Fondo de Cultura Económica.

Guerra, F.-X. (1998). México: del antiguo régimen a la revolución (2 vols.). México: Fondo de Cultura Económica.

Gibbon, E. (1949). Autobiografía (trad. de A. Dorta). México/Buenos Aires: Espasa Calpe.

Guicciardini, F. (1969). The History of Italy (trad. e introd. S. Alexander). Nueva York: The Macmillan Company.

Ibargüengoitia, J. (1994). Los relámpagos de agosto. México: Joaquín Mortiz.

León-Portilla, M. (1984). Trece poetas del mundo azteca. México: Universidad Nacional Autónoma de México.

Lewis, O. (1963). The children of Sánchez. Autobiogaphy of a Mexican family. Nueva York: Vintage Books.

Ludlow, L. (coord.) (2002). Los secretarios de Hacienda y sus proyectos (1821-1933). México: Universidad Nacional Autónoma de México/Instituto Mora.

Martín H., M. A. (2008). La teoría de las generaciones de Ortega y Gasset: una lectura del siglo xxI. Tiempo y Espacio, 20, 98-110. Recuperado de http://revistas.ubiobio. cl/index.php/TYE/article/view/1736

Martínez, J. L. (1993). La expresión nacional. México: Consejo Nacional para la Cultura y las Artes.

Martínez, J. L. (1990). Hernán Cortés. México: Universidad Nacional Autónoma de México/Fondo de Cultura Económica.

Martínez, J. L. (1986). Netzahualcóyotl: vida y obra. México: Fondo de Cultura Económica. 
O'Gorman, E. (1974). Del amor del historiador a su patria. Palabras pronunciadas al recibir el Premio Nacional de Letras 1974. México: Centro de Estudios de Historia de México Condumex.

Ortiz Monasterio Prieto. J. (1991). Francisco Sosa, el género biográfico y la teoría del grande hombre. Secuencia, 21, 117-134. DoI: http://dx.doi.org/10.18234/secuencia. v0i21.360

Ortiz Monasterio Prieto, J. (1993a). Historia y ficción. Los dramas y novelas de Vicente Riva Palacio. México: Instituto Mora/Universidad Iberoamericana.

Ortiz Monasterio Prieto, J. (1993b). Los médicos charlatanes en el siglo XIX. El caso del viajero inglés William Hardy. En A. Garritz et al., Un hombre entre Europa y América. Homenaje a Juan Ortega y Medina (pp. 315-326). México: Universidad Nacional Autónoma de México.

Ortiz Monasterio Prieto, J. (1996a). Biografía e historiografía literaria en Francisco Sosa. En J. Ruedas de la Serna (coord.), Historiografía de la literatura mexicana. México: Universidad Nacional Autónoma de México.

Ortiz Monasterio, Prieto, J. (1996b). La literatura como profesión en México en el siglo XIX. En Y. Bache Cortés et al. (eds.), Memoria Coloquio Internacional Manuel Gutiérrez Nájera y la Cultura de su Tiempo. México: Universidad Nacional Autónoma de México.

Ortiz Monasterio Prieto, J. (2002). Mariano Riva Palacio en el Ministerio de Hacienda. En L. Ludlow (coord.), Los secretarios de Hacienda y sus proyectos (1821-1933) (vol. 1, pp. 229-246). México: Universidad Nacional Autónoma de México/Instituto Mora.

Ortiz Monasterio Prieto, J. (2004). México eternamente. Vicente Riva Palacio ante la escritura de la historia. México: Instituto Mora/Fondo de Cultura Económica.

Ortiz Monasterio Prieto, J. (2008). ¿Zapata en Chinameca? En El libro rojo (t. 1, pp. 506-520). México: Fondo de Cultura Económica.

Ortiz Monasterio Prieto, J. (2009). Charlas de café con Vicente Guerrero. México: Grijalbo.

Pérez de Villagrá, G. (1989). Historia de la Nueva México. Madrid: Historia.

Plutarco (1973). Vidas paralelas. En Biógrafos griegos (trad. del griego y notas por A. Sanz Romanillos, J. Ortiz y Sanz y J. M. Riaño). Madrid: Aguilar.

Reyes Heroles, J. (1982). El liberalismo mexicano. México: Fondo de Cultura Económica. Riva Palacio, V. (1884-1889). México a través de los siglos. Barcelona: Ballescá.

Riva Palacio, V. (1946). El libro rojo. México: Editorial Leyenda.

Riva Palacio, V. (1979). Cuentos del general y Los ceros (pról. y notas de José Ortiz Monasterio). México: Promexa.

\section{()(1) $(3$}


Riva Palacio, V. (1997). Calvario y Tabor. Novela histórica y de costumbres. México: Instituto Mora/Instituto Mexiquense de Cultura/Consejo Nacional para la Cultura y las Artes/Universidad Nacional Autónoma de México.

Santos Rivera, G. (1984). Memorias. México: Grijalbo.

Schowb, M. (1922). Vidas imaginarias (trad. R. Carrera). México: Cultura.

Sierra, J. (dir.) (1900). México: su evolución social. Inventario monumental que resume en trabajos magistrales los grandes progresos de la nación en el siglo XIX. México: Ballescá y Cía.

Sobarzo, A. (2012). Deber y conciencia. Nicolás Trist, el negociador norteamericano en la guerra del 47. México: Fondo de Cultura Económica.

Sosa, F. (1996). Las estatuas de la Reforma (pról. E. de la Torre Villar). México: Universidad Nacional Autónoma de México.

Stone, L. (1986). El pasado y el presente. México: Fondo de Cultura Económica.

Vico, G. (1970). Autobiografía. Buenos Aires: Aguilar.

Zárate Toscano, V. (2000). Los nobles ante la muerte en México 1750-1850. México: Instituto Mora/El Colegio de México.

\section{OTRAS FUENTES}

\section{Bibliografía}

Alamán, L. et al. (1853-1856), Diccionario universal de historia y de geografía: obra dada a luz en España por una sociedad de literatos distinguidos, y reunida y aumentada considerablemente para su ubicación en México con noticias históricas, geográficas, estadísticas y biográficas sobre las Américas en general y especialmente sobre la República Mexicana. México: Tipografía de Rafael/Librería de Andrade.

Hurtado, F. de M. (coord.) (1984). Diccionario biográfico del gobierno mexicano. México: Presidencia de la República-Dirección General de Comunicación Social-Unidad de la Crónica Presidencial.

Ortiz Monasterio Prieto, J. (2005). La revolución de la lectura durante el siglo XIX en México. Historias, 60, 57-76.

Robertson, W. (2012). Iturbide de México. México: Fondo de Cultura Económica. 